\title{
"El que murió cuando nacía". Reloj de un infante perfecto: Carlos de Austria (1607-1632) en los elogios fúnebres
}

\author{
"El que murió cuando nacía". Mirror of a perfect infant: Charles of \\ Spain (1607-1632) in the eulogies
}

\author{
(D) MARION DUCHESNE \\ Universidad de Caen Normandie \\ marion.duchesne@hotmail.fr
}

Resumen: Si bien falleció antes de alcanzar fama, el infante Carlos de Austria (1607-1632) fue celebrado universalmente por los ingenios de su época. Tanta consideración sorprende - sobre todo si se toma en cuenta la poca atención que le dedicó la historiografía - e invita a examinar los panegíricos fúnebres que elogiaron su memoria. Estos publican un modelo de conducta del infante de Castilla - entre apoyo a las ideas conceptualizadas bajo el régimen de Olivares y a veces tenue crítica a las mismas - a la vez que esbozan el perfil biográfico de la más discreta de las personas reales que vivió bajo el reinado de Felipe IV.

Palabras clave: Infante Carlos de Austria, Felipe IV, elogios fúnebres, ejemplaridad, biografía.

\begin{abstract}
Although he died before achieving renown, the Infante Carlos of Austria (16071632) was widely celebrated by the spirits of his time. Such recognition is surprising especially considering the little attention that historiography has devoted to him- and invites us to examine the funeral eulogies that praised his memory. These publish a model of conduct for the Infante of Castile. Thus, between support for the ideas conceptualized under the Olivares regime and a slightly toned-down criticism, the eulogies actually sketch the biographical profile of the most discreet person among the Royals who lived during the reign of Philip IV.
\end{abstract}

Keywords: Infante Carlos of Austria, Philip IV, eulogies, exemplary, biography.

\footnotetext{
${ }^{1}$ Bocángel y Unzueta, Gabriel, Retrato panegírico del serenissimo señor Carlos de Avstria, Infante de España, Príncipe de la Mar, Madrid, imprenta del reino, 1633, f. 2r.
}

Recibido: 16 de julio de 2020; aceptado: 16 de enero de 2021; publicado: 31 de marzo de 2021.

Revista Historia Autónoma, 18 (2021), pp. 75-89

e-ISSN: 2254-8726; https://doi.org/10.15366/rha2021.18.004 


\section{Introducción}

"Que no es la vida poca por ser breve, Porque en siendo cabal la vida, es mucha". ${ }^{2}$

La carencia de laureles militares con los que adornar el nombre del infante Carlos de Austria ${ }^{3}$, fallecido a los veinticuatro años sin haber salido nunca de Palacio, aparece contrabalanceada en este quiasmo en verso de Bocángel por la perfección de la vida del hermano segundo de Felipe IV que, según el poeta, por sí sola justifica que se la aplauda. Bocángel no fue el único en homenajear al quinto hijo de Felipe III y de Margarita de Austria-Estiria, sino que lo hicieron, en obras de extensión variable, los mayores ingenios de la época. Sin pretender reflejar aquí una lista exhaustiva de todas las existentes, referenciamos a continuación las obras que hemos identificado, clasificándolas según su género:

\section{Panegíricos poéticos de larga extensión}

Bocángel y Unzueta, Gabriel, Retrato panegírico del serenissimo señor Carlos de Avstria, Infante de España, Príncipe de la Mar, Madrid, imprenta del reino, 1633.

Calderón de la Barca, Pedro, Elegía en la muerte del señor Infante don Carlos. Al señor Infante Cardenal por don Pedro Calderón de la Barca4.

Cantañazor, Juan de, Inconstancia del tiempo, y brevedad incierta de la vida. A la muerte delSerenissimo Señor D. Carlos de Austria, infante de España. Al eminentiss. y reverendiss. señor D. Francisco Barberino cardenal de la S. R. Yglesia, y su vice cancellario, Roma, Juan Battista Roblet, 1632.

Muñoz, Antonio, Tres romances en que se declara el sentimento general que ha causado la muerte del serenissimo Infante D. Carlos, Barcelona, Esteban Liberos, 1632.

Pellicer de Ossau Salas y Tovar, José, Oración fúnebre en la mverte del serenissimo señor don Carlos de Avstria infante de las Españas, príncipe de la mar, Madrid, Se, 1632.

Rodríguez de León, Juan, Panegyrico augusto, castellano latino, al Serenissimo Infante Cardenal don Fernando de Austria, llanto funebre en las muertes de los Catolicos Monarcas, Filipo III y Margarita, repetido en la del Infante don Carlos..., México, Bernardo Calderón, 1639.

\footnotetext{
${ }^{2}$ Ibidem, f. $15 \mathrm{v}$.

${ }^{3}$ Nacido el 15 de septiembre de 1607, el infante Carlos de Austria falleció el 30 de julio de 1632 a las dos de la madrugada, sucumbiendo a una enfermedad que había durado varias semanas.

${ }^{4}$ Utilizamos la edición digital elaborada en 2012 por Blanca Oteiza, disponible en la Biblioteca Virtual Miguel de Cervantes. http://www.cervantesvirtual.com/nd/ark:/59851/bmcw38f7 [consultado el 25 de junio de 2020]
} 
Marion Duchesne, "El que murió cuando nacía. Reloj de un infante perfecto..."

\begin{tabular}{|c|}
\hline Poemas sueltos \\
\hline $\begin{array}{l}\text { Borja y Aragón, Francisco de, "En la muerte del señor Infante don Carlos”, “Al Rey Nuestro } \\
\text { Señor en la muerte de Su Alteza” y "Glosa VIII. La gloria no morirá” en Las obras en verso de } \\
\text { Francisco de Borja, príncipe de Esquilache (...), Amberes, imprenta plantiniana de Balthasar } \\
\text { Moreto, } 1663 \text {, f. } 47,168 \text { y } 385 \text {. }\end{array}$ \\
\hline $\begin{array}{l}\text { Faria e Sousa, Manuel, "En la muerte del Infante don Carlos año 1632” en Fuente de } \\
\text { Aganipe o Rimas varias divididas en siete partes. Parte segunda, Madrid, Juan Sánchez, } \\
\text { 1644, f. } 69 \mathrm{v} .\end{array}$ \\
\hline $\begin{array}{l}\text { Hurtado de Mendoza, Antonio, "A la muerte del Ynfante do } \\
\text { Edición y prólogo de Rafael Benítez Claros, III, Madrid, Gráfic }\end{array}$ \\
\hline $\begin{array}{l}\text { Moncayo y Gurrea, Juan, “A la muerte del señor infante Carlos. Soneto" en Rimas, Zaragoza, } \\
\text { Diego Dormer, 1652, f. } 29 \text {. }\end{array}$ \\
\hline $\begin{array}{l}\text { Paravicino y Arteaga, Hortensio Félix, "A la muerte del Infante Carlos" en Obras posthumas, } \\
\text { divinas y humanas de don Felix de Arteaga, 1641, f. 68v. }\end{array}$ \\
\hline $\begin{array}{l}\text { Quevedo, Francisco de, "Túmulo al serenísimo Infante Don Carlos" y "Al mismo señor } \\
\text { infante" en Obra poética, edición de José Manuel Blecua, Madrid, Castalia, 1969, tomo I, } \\
\text { pp.442-443. }\end{array}$ \\
\hline $\begin{array}{l}\text { Sivori, Tomás, “A la muerte yntenpestiua del SSmo S. Ynfante don Carlos en } 29 \text { de julio en el } \\
\text { año } 1632 \text { " en Rimas, BNE, Ms. 2610, f. 35r. }\end{array}$ \\
\hline $\begin{array}{l}\text { Solís y Rivadeneyra, Antonio de, "A la muerte del señor Infante don Carlos, considerando este } \\
\text { infortunio a vista de la quietud misteriosa de su vida" en Poesías sagradas y profanas, Madrid, } \\
\text { Ediciones Goyeneche, } 1692 \text {, f. } 7 \text {. }\end{array}$ \\
\hline Narración cronística de la muerte del infante Carlos \\
\hline $\begin{array}{l}\text { Novoa, Matías de, Historia de Felipe IV, rey de España, edición de Cánovas del Castillo } \\
\text { en Colección de documentos inéditos, tomo LXIX, Madrid, Imprenta de Miguel Ginesta, } \\
\text { 1875,pp. 190-208. }\end{array}$ \\
\hline Biografía completa del infante Carlos \\
\hline $\begin{array}{l}\text { Hurtado de Mendoza, Antonio, Las señas del Señor Infante Don Carlos que esté en el cielo, } \\
\text { British Library, Egg. 338, f. 172r-202 } \mathrm{v}^{5} \text {. }\end{array}$ \\
\hline
\end{tabular}

\footnotetext{
${ }^{5}$ Este manuscrito de Hurtado de Mendoza, que hemos descubierto recientemente en los fondos de la British Library, resulta de gran valor para el estudio de los primeros años del reinado de Felipe IV. En efecto, más allá de constituir la única biografía del segundo hermano de Felipe IV, presenta una nueva visión acerca de la relación entre el valido y los infantes de Castilla, ya que, Hurtado de Mendoza, además de poeta y secretario de Estado, era hechura del Conde Duque, a la inversa de Matías de Novoa, a partir de cuyo relato se ha interpretado mayoritariamente la imagen de una enemistad casi visceral entre los infantes y el valido. Productos de facciones opuestas, las crónicas de Hurtado de Mendoza y de Matías de Novoa se contrabalancean, lo que nos permite intuir una realidad histórica que podría encontrarse a medio camino entre las dos.
} 
No deja de llamar la atención la relevancia de esta producción literaria — significativa tanto por su abundancia como por la fama de sus autores - teniendo en cuenta la mediocre, por no decir inexistente, posteridad de esta persona real. Hijo de rey, hermano de rey y de reinas, el infante Carlos de Austria no se ha beneficiado de la indulgencia de la historiografía y son numerosos los calificativos — "tímido y retrasado" 6 , "apocado", "pobre mentecato", entre otros - que desvalorizan su inteligencia del infante, a pesar de que gastara su tiempo libre en escribir versos ${ }^{9}$ celebrados por sus contemporáneos ${ }^{10}$. El silencio que envuelve su vida consecuencia tanto de su carácter callado como de una imposición institucional— explica en parte estas interpretaciones expeditivas ${ }^{11}$.

En todo caso, si no bastara recordar el estatus de heredero de la corona que ostentó casi toda su vida para convencernos de la trascendencia de su figura política ${ }^{12}$, para nada insignificante ${ }^{13}$, la atención literaria que conoció su muerte es una prueba adicional de la necesidad de contribuir a revelar este enigma político: de haber sido un infante de importancia tan periférica como así

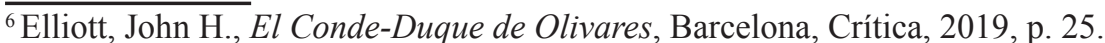

${ }^{7}$ Aldea Vaquero, Quintín, "Don Fernando de Austria, cardenal y arzobispo de Toledo (1619-1641). Razones de su nombramiento", en Fernández Albaladejo, P., Martínez Milán, J. y Pinto Crespo, V. (coord.), Política, religión e inquisición en la España moderna. Homenaje a Joaquín Pérez Villanueva, Madrid, Ediciones de la Universidad autónoma de Madrid, 1996.

${ }^{8}$ Marañón, Gregorio, El Conde-Duque de Olivares (la pasión de mandar), Madrid, Espasa-Calpe, 2006, p. 316.

${ }^{9}$ Unos cuantos poemas del infante llegaron hasta nosotros: "A Anarda", en Castro y Rossi, Adolfo, El Conde-duque de Olivares y el rey Felipe IV, Cádiz, Imprenta, librería y litografía de la revista médica, 1846, p. 104; "Al toro que mató el rey", editado con el título "A su hermano el rey don Felipe IV por la fiera que mató de un arcabuzazo", en Los príncipes de la poesía española: colección de poesías en su mayor parte inéditas de príncipes, grandes y títulos, recogidas por Juan Pérez de Guzmán, Madrid, tipografía de Manuel Ginés Hernández, 1892, p. 220; "Soneto q[ue] hiço el S[eñor] Ynfante de España don Carlos a la muerte de D. Luis Lasso, Conde de Añover", en Sánchez Cantón, Francisco J., Catálogo de las pinturas del instituto de Valencia don Juan, Madrid, 1923, p. 120. Don Carlos envió algunos de sus poemas a José Pellicer y Tovar, pero prohibió que se publicaran. Véase Arco y Garay, Ricardo del, La Erudición española en el siglo XVII, Tomo I, Instituto Jerónimo Zurifa, Consejo Superior de Investigaciones Científicas, 1950, p. 494. Según Hurtado de Mendoza, al ordenar su testamento dos días antes de que muriera, también mandó que fueran destruidos "algunos papeles en que se ejercitaba más su ingenio" que se encontraban en un escritorio cerrado con llave. Véase Hurtado de Mendoza, Las señas... op. cit., f. 199r.

${ }^{10}$ Numerosos ingenios elogiaron y glosaron los poemas del infante: Faria e Sousa, Manuel, "Al haber hecho el infante D. Carlos un soneto lastimado del rigor de Anarda" y "Al Infante D. Carlos por Galan, i por poeta igualmente", en Fuente de Aganipe o Rimas varias divididas en siete partes. Parte primera, Madrid, Juan Sánchez, 1644, f. 75r; Gracián, Baltasar, Agudeza y arte de ingenio, "discurso XIX", en Obras completas, Edición, introducción y notas de Santos Alonso, Cátedra, 2011, p. 559; López de Vega, Antonio, "Congratulación a los Poetas. Enhorabuena a la poesía por haberse dignado el serenísimo infante don Carlos de ejercitar su ingenio en ella", en El perfeto señor, Sueño político con otros varios discursos y poesías varias, Madrid, Imprenta Real, 1652, f. 227; Ulloa y Pereira, Luis de, "En aplauso del soneto del señor Infante", en Obras, prosas y versos, 1674, f. 26-27; Vega Carpio, Lope de, "Égloga panegírica al epigrama del Infante Carlos", ed. de Felipe B. Pedraza Jiménez en La vega del Parnaso, edición crítica y anotada del Instituto Almagro de teatro clásico, dirigida por Felipe B. Pedraza Jiménez y Pedro Conde Parrado; con la colaboración de José Cano Navarro, Javier García Rodríguez, Christian Giaffreda, et al., tomo III, Cuenca, Ediciones de la Universidad de Castilla-La Mancha, 2015. La jocosa conclusión con la que F. Pedraza Jiménez cierra el retrato que la historiografía elaboró del infante nos parece plenamente adaptada para zanjar el tema de su poca inteligencia: "En fin, eran tiempos aquellos en los que el más tonto hacía sonetos", p. 329. ${ }^{11}$ La biografía del infante Carlos descansa en una paradoja historiográfica: si bien resulta posible reconstruir casi día a día su trayectoria vital física (por ser la misma que la de Felipe IV), se desconoce casi por completo la esencia íntima de su individualidad.

${ }^{12}$ S. Martínez Hernández fue el primero en subrayar su importancia. Véase Martínez Hernández, Santiago, “"Los más infames y bajos traidores...': el desafío aristocrático al proyecto olivarista de regencia durante la enfermedad de Felipe IV (1627)", en Investigaciones históricas, 34 (2014), p. 63. «https://revistas.uva.es/index.php/invehisto/ article/view/449»" [Consultado el 25 de junio de 2020]

${ }^{13}$ Elliott, John H., El Conde-Duque... op. cit., p. 313.
} 
lo postula parte de la historiografía: ¿por qué tantos poetas iban a aceptar el "reto"14 de escribir sus elogios fúnebres?

Dentro de los límites de este artículo, nos proponemos examinar el alcance ideológico de algunas de estas obras que, aun siendo circunstanciales, no dejan de tener significado político ${ }^{15}$. En efecto, al igual que Bocángel y a través de la celebración de las virtudes de don Carlos, varios autores pretendieron edificar una institución del hermano del rey que, además de homenajear a la persona real desaparecida, sirviera para publicitar cierto modelo del infante de Castilla. A este respecto, nos interesa analizar en qué medida se adecúan las representaciones que de don Carlos construyen estos panegíricos fúnebres a las características de un estatus del infante de Castilla que nueva y paulatinamente fue elaborando el binomio rey-valido durante la década anterior (1621-1631). Efectivamente, no desconocemos las inquietudes que el CondeDuque de Olivares alimentó para con los infantes Carlos y Fernando que, si bien eran jóvenes adolescentes cuando Felipe IV subió al trono, a finales de la década 1620 habían alcanzado la edad adulta sin cargo alguno. Dicha cuestión, que hoy se conoce como "el problema de los infantes"16 originó una extensa reflexión desde los círculos más secretos del poder, la cual llegó hasta nosotros de manera parcelaria a través de valiosas consultas de Estado y, también, mediante los famosos memoriales de Olivares ${ }^{17}$. Por ello, cotejaremos estos últimos con los elogios fúnebres seleccionados ${ }^{18}$, estableciendo un diálogo que nos permitirá exponer cómo, a través de las características de un infante liberal, obediente, callado y que está al servicio de la Monarquía Hispánica, los panegiristas construyeron un modelo canónico del infante de Castilla a la vez que esbozaron un perfil biográfico del infante Carlos de Austria, entre el apoyo a las ideas conceptualizadas bajo el régimen de Olivares y, a veces, la sutil crítica a las mismas.

\footnotetext{
${ }^{14}$ Matas Caballero, Juan, "Marino y Bocángel: del Ritratto del duca di Savoia al Retrato panegírico del infante don Carlos de Austria", en Criticón, 132 (2018). https://doi.org/10.4000/criticon.3976: "Para todos los poetas, pero en especial para Gabriel Bocángel, debió de suponer un verdadero 'reto' —como había afirmado Dadson- escribir un poema panegírico en honor de un príncipe que murió a una edad tan temprana que su currículum (heroico, político o artístico) estaba prácticamente en blanco y que, para colmo, era "un muchacho tímido y retrasado"”.

${ }^{15}$ Sobre el vínculo entre poesía laudatoria y poder, remitimos a la "Presentación" de Jesús Ponce Cárdenas al monográfico El panegírico en el Siglo de Oro: nuevas investigaciones, en Criticón, 132 (2018). https://doi. org/10.4000/criticon.3669

${ }^{16}$ Expresión acuñada por J. H. Elliott y retomada por la historiografía posterior. Por ejemplo, pensamos en el título del capítulo 6 de Hoffman, Martha K., Raised to rule. Educating royalty at the Court of the Spanish Habsburgs, 1601-1634, Louisiana State University Press, 2011, pp. 147-182: "The Problem of the Infantes".

${ }^{17}$ Utilizaremos los memoriales editados por J. H. Elliott y José F. de la Peña en Memoriales y cartas del Conde Duque de Olivares. Vol. 1. Tomos 1 y 2, Política interior, 1621-1645, Madrid, Centro de estudios Europa hispánicas, M. Pons Historia, 2013; otros dos editados por Valladares en Semanario erudito que comprehende varias obras inéditas, [...] de nuestros mejores autores antiguos y modernos, Tomo XXIX, Madrid, Antonio Espinosa, 1790, pp. 239-241 y pp. 250-255; y también uno editado por Marañón en El Conde-Duque... op. cit., p. 564.

${ }^{18}$ Las obras de larga extensión, tanto poéticas como cronísticas, por definición, son las que concentran nuestra atención.
} 
2. Un infante liberal

\section{1. "Era la esperanza de la corte"19}

A las diez de la noche, el 30 de julio de 1632, ante la mayor nobleza de Castilla congregada para rendir su último tributo, se abrieron las puertas de Palacio para dejar paso a una comitiva fúnebre ${ }^{20}$ que, a la luz de hachas y faroles, había de llevar hasta San Lorenzo el Real el ataúd del infante Carlos, fallecido aquel mismo día. El cuerpo iba a ser sepultado en un túmulo que, hoy en día, sigue ostentando la frase siguiente: “Abre sus manos al necesitado y tiende sus brazos al pobre" ${ }^{21}$.

La caridad fue por tanto la virtud teologal elegida para adornar la eternidad del infante Carlos. Una inscripción que — según parece - se resuelve tan anodina como el propio infante, ya que se trata de una de esas virtudes comúnmente exigidas a los príncipes en todos los relojes, y de escasa originalidad en un miembro de la católica casa de Austria. El carácter insignificante de este epitafio se ve reforzado en comparación con las virtudes marciales que glorifican el túmulo del Cardenal Infante Fernando, héroe de la guerra de los Treinta Años ${ }^{22}$.

Sin embargo, sorprende advertir que entre las virtudes tópicas que sirven de cimiento para construir un panegírico del infante, destaca sobremanera la virtud de liberalidad, que no es más que una extensión de la caridad. De hecho, la casi totalidad de los elogios fúnebres inventariados celebran la de don Carlos que, si bien no realizó empresas tan grandes como las que apelaba su nombre, se ilustró en obras más humildes y desconocidas. Estas no le abrieron las puertas de la posteridad, pero le granjearon el reconocimiento de numerosos contemporáneos.

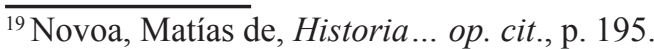

${ }^{20}$ Para saber quiénes formaron parte de este cortejo, véase Archivo General de Palacio [en adelante, AGP], sección histórica, Caja 56, Exp. 25.

${ }^{21}$ Rodríguez Díez, José, "Epitafios del Panteón de Infantes del Monasterio del Escorial y sus fuentes bíblicas", en Campos y Fernández de Sevilla, F.J. (coord.), El mundo de los difuntos: culto, cofradías y tradiciones, Vol. 2, Ediciones Escurialenses, 2014, p. 846: "Manum suam aperuit inopi et palmas suas extendit ad pauperem [Prov $31,20]^{\prime}$.

${ }^{22}$ Ibidem, p. 849: "Dilatavit gloriam populo suo et induit se loricam sicut gigas et protegebat castra gladio suo (Dilató la fama de su pueblo; vistió la coraza como un gigante, ... protegiendo sus campamentos con la espada [1Mac 3, 3a])". Existen varios estudios monográficos sobre el Cardenal Infante Fernando. Examinan sobre todo la segunda parte de su vida, la que transcurrió fuera de Palacio: Van der Essen, Alfred, Le Cardinal-infant et la politique européenne de l'Espagne, 1609-1641. Tome Premier, 1609-1634, Bruxelles, Éditions Universitaires, Les Presses de Belgique, 1944; actualmente está realizándose una tesis en la Universidad Jaime I por Isabel María Lloret Sos bajo la dirección de V. Mínguez: Iconografía, literatura y fiesta. El Cardenal Infante Don Fernando de Austria, Héroe de Nördlingen (1609-1641). En lo concerniente a la vida del infante en Flandes, véanse, por ejemplo, los trabajos de Alicia Esteban Estríngana y de René Vermeir. Q. Aldea Vaquero considera de manera más detallada los jóvenes años del infante. Véase Aldea Vaquero, Quintín, El cardenal infante don Fernando o la formación de un príncipe de España, Discurso leído el día 16 de febrero de 1997 en su recepción publica por el excmo. Sr. D. Quintín Aldea Vaquero, SJ. y contestación por el Excmo. Sr. D. Felipe Ruiz Martín, Zamora, Real Academia de la Historia, 1997. También está en prensa la indispensable correspondencia de Olivares con el infante editada por J.H. Elliott y F. Negredo del Cerro: Memoriales y Cartas del Conde Duque de Olivares, t. III: Correspondencia con el Cardenal Infante don Fernando (1635-1641), Madrid, Marcial Pons-CEEH [2021].
} 
Así, los 400 ducados que desde agosto de 1621 recibía cada mes para sus entretenimientos ${ }^{23}$ eran "repartidos antes que llegados" ${ }^{24}$, dinámica que no parece haber sufrido cambio cuando aumentaron sus rentas en noviembre de 1626 en que Felipe IV le atribuyó los frutos de la orden de San Juan ${ }^{25}$. Estas rentas se gastaban en favores y mercedes, y beneficiabana personas de diferente estado ${ }^{26}$, entre las cuales se encontraban algunos de sus panegiristas, como Juan de Cantañazor ${ }^{27}$. Entendemos así que el sustento y la salvación de muchos cortesanos dependieron de la generosidad del infante $\operatorname{Carlos}^{28}$.

\subsection{Una liberalidad bajo control}

Los panegiristas del infante también insisten en la justa contrapartida de aquella liberalidad, es decir, el amor que los vasallos - tanto el pueblo como la nobleza - le profesaban a don Carlos $^{29}$. Más allá de ser un motivo fúnebre, cabe cuestionar este sentimiento poniéndolo en relación con los juegos de poder y de influencia en la corte.

En efecto, la liberalidad era una virtud que le permitía al príncipe granjearse la voluntad de los vasallos, así como reforzar su autoridad y engrandecer su reputación. De hecho, asociada con la justicia, la liberalidad participaba de la fabricación de la majestad, por lo que constituía la virtud real por antonomasia ${ }^{30}$. Comprendemos así por qué uno de los medios claves que cita Olivares para controlar a los infantes en su "Gran memorial" consiste en mantenerlos bajo dependencia financiera, aunque respetando siempre su dignidad: "El darles V. M. hacienda ha de ser con limitación, pero no con miseria"31. Tal exhortación se hace eco de la tesis desarrollada por Belarmino en su obra Del officio del príncipe christiano 32 : "ninguna regla puede hallarse más

\footnotetext{
${ }^{23}$ AGP, AD, Cuentas generales, Leg. 6729, sf: “Otra de 800 du[cados] para darlos a los s[eñores] ynfantes Don Carlos y ynfanta doña Maria a cada uno 400 du[cados] de los meses de abril y mayo del d[icho] año [1621]"; "Y den otra de 400 du[cados] para darlos a los s[eñores] ynfantes del mes de ag[osto] y es general para que se entreguen cada mes desde principio del d[icho] ag[osto]".

${ }^{24}$ Hurtado de Mendoza, Antonio, Las señas... op. cit., f. $181 \mathrm{v}$.

${ }^{25}$ Sobre la costumbre de atribuir el Priorato de San Juan a personas reales, véase Aznar Martínez, Daniel y Fernando Sánchez Marcos, "Don Juan José de Austria, bastardo regio y Gran Prior. La consolidación del poder real sobre la Orden de San Juan en la época de Felipe IV", en Rivero Rodríguez, Manuel (coord.), La Orden de San Juan, Polifemo, 2009, pp. 1555-1581.

${ }^{26}$ Se puede tener un panorama de las personas que fueron favorecidas por el infante en AGP, Sección Fondo del Infante don Gabriel (IDG), Secretaría, Leg. 764.

${ }^{27}$ En su dedicatoria al cardenal Barberino, Cantañazor explica las razones que le condujeron a escribir su obra. Cantañazor, Juan de, Inconstancia del tiempo... op. cit. sf.: "Y el segundo [motivo], por ser este discurso hecho a la muerte del Serenísimo Señor Infante D. Carlos, que tan aficionado fue a V. E. y de quien yo tantos favores, y mercedes recibido había".

${ }^{28}$ Pellicer y Tovar, Hurtado de Mendoza y Novoa le llaman el "abrigo" o el "amparo" de Palacio. También señalan que "viv[ían] por él muchos" y que muchos "respiraban en aquellas manos". Véase Pellicer y Tovar, José, Oración fúnebre... op. cit., f. 14r; Hurtado de Mendoza, Antonio, Las señas... op. cit., f. 181v y f. 202v; Novoa, Matías de, Historia ... op. cit., p. 195.

${ }^{29}$ Muñoz, Antonio, Tres romances..., op. cit., sf; Pellicer y Tovar, José, Oración fúnebre... op. cit., f. 14v.

${ }^{30}$ Sobre el concepto de liberalidad, véase Merle, Alexandra, "La libéralité du prince dans la pensée politique espagnole au XVIe siècle”, enn Le Verger, 2 (2012); véase también Bermejo Cabrero, José Luis, Poder político y administración de justicia en la España de los Austrias, Madrid, Ministerio de Justicia, Secretaría General Técnica, 2005, pp. 39-43.

${ }^{31}$ Memoriales y cartas ... op. cit., p. 90.

${ }^{32}$ En 1624, el mismo año en que J. H. Elliott fecha el "Gran Memorial", Miguel de León Soarez publicó la traducción castellana de este texto dedicada — precisamente - al Conde Duque de Olivares. Sobre las dudas que
} 
segura que conoce el príncipe a sus hermanos por hermanos, y tratarlos como tales, y no como a siervos, ni tampoco como a señores" ${ }^{33}$. Estas prescripciones se aplicaron en el caso de los hermanos de Felipe IV, ya que, muy lejos de ser señores como los Fils de France, que recibían tierras - o apanages - en compensación simbólica por su renunciaal trono ${ }^{34}$, los infantes de Castilla gozaban de pocas rentas ${ }^{35} \mathrm{o}$, cuando las gozaban, el rey controlaba su administración ${ }^{36}$. Reforzando la dependencia económica de los infantes al rey, se trataba de reducir su capacidad para provocar desórdenes que dañaran a la Monarquía Hispánica. En particular se buscaba evitar lo que Pellicer y Tovar no duda en resaltar en su Oración fúnebre es decir lo "amado, alabado y engrandecido" 37 que resultó el infante gracias al poder de atracción de su liberalidad. Sin embargo, en vez de ilustrar las ideas olivaristas de una ley natural y fatídica que empujaría inexorablemente a los infantes hacia la destrucción de la Monarquía hispánica ${ }^{38}$, alabar la largueza del infante Carlos le permitió a Pellicer y Tovar, como a los demás panegiristas, insistir en el carácter desinteresado de una práctica que se efectuaba "sin ruido"39 y "no por otros fines ni más industria que por virtud propia"40 "pues sus rentas y cuanto poseía, por primicias ofrecía a Dios con remediar a pobres y lo restante, si acaso le sobraba, (que era tan liberal que era imposible) a los pies del hermano lo ponía que como a Padre amaba"41.

\footnotetext{
se plantean con respecto a la autoría y a la fecha de redacción de este documento, véase Rivero Rodríguez, M., "El 'Gran Memorial' de 1624, dudas, problemas textuales y contextuales de un documento atribuido al conde duque de Olivares", Libros de la Corte, $\mathrm{N}^{\circ}$. 4, 2012, pp. 48-71. No tenemos pruebas para afirmar que existe una relación intertextual entre los textos de Belarmino y de Olivares, sin embargo, ambos esquemas de pensamiento presentan demasiadas similitudes como para no subrayarlo.

${ }^{33}$ Belarmino, Roberto, Del officio del príncipe christiano (...), Madrid, Juan Gonzalez, 1624, 33v-34r.

${ }^{34}$ Véase Deroche, Alexis, L'apanage royal en France à l'époque moderne, Paris, éditions Panthéon-Assas, 2013. Los apanages no solo eran una fuente importante de riquezas, sino también de prestigio y de prerrogativas; las cuales - en conjunto- permitían destacar a los hijos segundos del rey de los miembros de la alta nobleza y de los príncipes de la sangre.

${ }^{35}$ Remitimos a la nota a pie de página número 23.

${ }^{36}$ La junta que administraba las rentas del Priorato de San Juan en nombre del infante Carlos solo actuaba por decreto del rey. Entre otras cosas, Felipe IV aprobaba las decisiones tomadas primero por su hermano; también decidía cuánto dinero se había de distribuir al infante cada mes, así como otorgaba que se le distribuyera excepcionalmente sumas más importantes para saldar deudas contraídas jugando a los trucos. Existen numerosos ejemplos de lo expuesto en AGP, IDG, Secretaría, Leg. 711/14 y Leg. 711/15. Lo mismo ocurría en la administración de las rentas del arzobispado de Toledo. Según Pérez Bustamante, Ciriaco, La España de Felipe III, tomo XXIV de la Historia de España, dirigida por Menéndez Pidal, Madrid, Espasa-Calpe, 1979, p. 179: "El rey Felipe IV proveía los cargos y disponía a su antojo todo lo relativo a la archidiócesis por medio de coadministradores de su confianza".

${ }_{37}$ Pellicer y Tovar, José, Oración fúnebre... op. cit., f. 14r.

${ }^{38}$ Las ideas del Conde Duque de Olivares se resuelven contradictorias: en varios memoriales, a la vez que denuncia el peligroso determinismo vital de los infantes, también alaba su buen natural. Separa la persona y la dignidad de los hermanos de Felipe IV. Esto se explica — en parte - porque el valido no puede atacar a las personas reales sin utilizar precauciones oratorias, a fortiori en los memoriales redactados antes de 1627, cuando aún no se les podía reprochar nada a los jóvenes infantes.

${ }^{39}$ Pellicer y Tovar, José, Oración fúnebre... op. cit., f. 14r.

${ }^{40}$ Novoa, Matías de, Historia ... op. cit., p. 195.

${ }^{41}$ Cantañazor, Juan de, Inconstancia del tiempo... op. cit., f. 58.
} 
3. Un infante obediente

\subsection{El primer vasallo de la Monarquía Hispánica}

Según el modelo de infante de Castilla que se elaboró durante los primeros años del reinado de Felipe IV, la primera virtud que debía perfeccionar un segundogénito real, por encima de todo, era la obediencia incondicional al rey. Precisamente es la que más destacan los apologistas de don Carlos, según los cuales las principales funciones del infante consistían en "amar, obedecer y servir al rey su hermano" ${ }^{2}$. Parece que las cumplió virtuosamente el hermano del monarca, ejerciendo tan "religiosamente el oficio de vasallo"43 que "aún no quisiera respirar sin orden [del rey]"44. Acató las órdenes de su hermano mayor hasta las puertas de la muerte, en una demostración de sumisión extrema narrada por varios panegiristas:

La paciencia, en tan rigurosas medicinas, que tal vez resistiéndolas por continuadas y fuertes, en diciéndole que su Majestad lo mandaban, era tanta la costumbre de su obediencia, que en lo más enajenado de los sentidos, al instante las admitía. ${ }^{45}$

Asimismo, mencionan la jura del príncipe Baltasar Carlos, evento en el que el infante dio una última muestra pública de su obediencia: le prestó homenaje a su sobrino ${ }^{46}$ manifestando tanto respeto "que hasta el menor vasallo pudiera hallar preceptos de sumisión y rendimiento a su rey" ${ }^{\prime 4}$. Que don Carlos ejemplificara a los Grandes y demás vasallos, como lo señala Hurtado de Mendoza en su crónica fúnebre, conecta con lo planificado por Olivares. En efecto, en su "Gran Memorial", el valido de Felipe IV elabora una estrategia de control que consiste en servirse de los infantes como unidad de medida para equilibrar las exigencias de una alta nobleza demandante ${ }^{48}$.

\footnotetext{
${ }^{42}$ Hurtado de Mendoza, Antonio, Las señas... op. cit., f. $201 \mathrm{v}$.

${ }^{43}$ Novoa, Matías de, Historia... op. cit., p. 196.

${ }^{44}$ Pellicer y Tovar, José, Oración fúnebre ... op. cit., f. 7r.

${ }^{45}$ Hurtado de Mendoza, Antonio, Las señas... op. cit., f. 197v; Novoa, Matías de, Historia ... op. cit., pp. 199-200:

"Era forzoso tomar alguna consolación para repararlas fuerzas y vivificar los espíritus, que los tenía muy decaídos, y dijo que no lo podía tomar; replicáronle que lo mandaba el Rey, y al punto obedeció, diciendo: - Si lo manda, tomarélo"; Pellicer y Tovar, José, Oración fúnebre... op. cit., f. 8v-9r: "Y para prueba de la obediencia de este príncipe, no hay que examinar más, que saber que estando ya muy descaecido de la dolencia que le acabó, (...), tan poseído del hastío el gusto, que le era penosísimo cualquier género de alimento que se le servía, (...), en oyendo recado, o precepto de su Hermano, o en conjurándole por su vida, era admirable piedad ver como se esforzaba, dando, aun entonces, las postreras luces su obediencia".

${ }^{46}$ Pellicer y Tovar, José, Oración fúnebre ... op. cit., f. 9v: "Tú fuiste el primero que en leal ceremonia, que en rito fiel, precediendo juramento como católico, pleito homenaje como caballero, doblada la rodilla, besaste la tierna cuanto poderosa mano del serenísimo don Baltasar Carlos”.

${ }^{47}$ Hurtado de Mendoza, Antonio, Las señas... op. cit., f. 191v.

48 “El Gran Memorial”, en Memoriales y cartas... op. cit., p. 89.
} 


\subsection{Un estatus paradójico y ambiguo}

Reflejo de lo anterior, los versos siguientes de Bocángel pueden leerse en clave política, siendo Felipe IV, el sol, y don Carlos, la rosa: "El Sol la mira, y ella [la rosa] vergonçosa, / El cuello humilla, y el favor compensa, / Agradecida sí, mas retirada, / Que flor podrá vivir, mas no embidiada" ${ }^{49}$. Estos elementos resumen hábilmente la situación ambigua del infante: a cambio de su sumisión, el rey le agasaja y le da su favor; dicho trato constituye el fundamento de la relación señor-vasallo. Sin embargo, el espacio político en el que se movía don Carlos no correspondía con las características del vasallaje, ya que, si le era inferior al rey, también era superior a todos los demás ${ }^{50}$, sin por ello ser señor de nada ni de nadie.

Estas coordenadas institucionales insólitas a las que se sometió don Carlos permitieron contener teóricamente a la alta nobleza ${ }^{51}$, la cual no podía pretender a más viendo tan resignado al primer infante de Castilla. Bien era consciente Olivares de lo criticable de tal situación ${ }^{52}$, inadecuada a la dignidad de un hijo de rey, pero la razón de Estado justificaba que se cometieran injusticias ${ }^{53}$.

\footnotetext{
${ }^{49}$ Bocángel, Gabriel, Retrato panegírico... op. cit., f. $8 \mathrm{v}$.

50 "Advertimientos del Conde-Duque al Señor Infante don Carlos" [1624], Apéndice XXI en Marañón, Gregorio, El Conde-Duque..., op. cit., p. 569: "Lo primero, Señor, aprenda V. A. que cuando habla con cualquiera que no sea el Rey mi señor, o la Reina nuestra Señora, o su primer hijo, cuando Dios con mucho bien se sirva de dárselos, todos los otros le caen a V. A. inferiores y que les es superior". Pellicer y Tovar tampoco le otorga otro superior que el rey en su Oración fúnebre... op. cit., f. 30r: "La Antigüedad me ofrece sus héroes (...). Mas yo hallo desigualdad tanta de sus méritos a los tuyos que no podré hacer con equidad la comparación fuera de ti mismo, pues tú solo te iguales, tu propio te compites, solo Felipe te excede, mira cuán grande es Felipe, pues tú le reconoces ventaja". ${ }^{51}$ Efectivamente, si bien el Conde Duque logró hacer que los infantes no fueran una fuente de envidia para la aristocracia, desplazó el problema hacia su propia persona. Sobre el tema de la oposición aristocrática al valimiento, véase Carrasco Martínez, Adolfo, "Los grandes castellanos ante el valimiento" en Aranda Pérez, Francisco José, La declinación de la monarquía hispánica en el siglo XVII: actas de la VII reunión científica de la fundación española de historia moderna, Cuenca, Universidad de Castilla-La Mancha, 2004.

${ }_{52}$ Otros versos de Bocángel parecen condenar el lugar ambiguo del infante en la corte. Ibidem, f. 4r: "Pues no a distancias oyes lo sonoro, / ( $\mathrm{O}$ tú siempre apartado, y nunca lejos!) / Quexas escucha de la triste España, / Que oy te asiste, bien q[ue] oy no te acompaña".

${ }^{53}$ La reflexión que el Conde Duque desarrolla sobre este tema puede leerse en "Papel que en continuación de los antecedentes firmó el Conde Duque para la junta sobre la educación y estado de los Señores Infantes Don Carlos y Don Fernando" en Valladares de Sotomayor, Antonio, Semanario erudito... op. cit., pp. 250-255.
} 
4. Un infante callado y enigmático ${ }^{54}$

\subsection{Retrato de un doble mudo del rey}

La dependencia de don Carlos con respecto al rey superó los límites de una subordinación puramente económica. Así permaneció el infante tan cercano a Felipe IV que nunca llegó a tener casa propia ${ }^{55}$, sino que los criados de su hermano le sirvieron toda su vida. También, desde 1621, le acompañaba en todos sus desplazamientos y viajes y aparecía con él en todos los actos públicos ${ }^{56}$. La semejanza física de los dos hermanos ${ }^{57}$ venía reforzada por el vestir, confeccionándose la misma ropa para el rey que para el infante ${ }^{58}$. Felipe IV parecía desdoblarse en su hermano, encarnando este una especie de doble real tanto física como simbólicamente, pero de manera casi etérea. Así pues, si era tan visible como el rey, no se le conocía voz propia. Institucionalmente dependiente, como acabamos de ver, también era don Carlos una persona muy callada. Numerosos son los panegiristas que insisten, de hecho, en el carácter reservado del infante que "era tan impenetrable que sus más allegados no le sondaran fácilmente, y tan soberano que no se rendía a descubrir afectos" ${ }^{59}$; tampoco se conocían sus inclinaciones, "siendo el verlo lo mismo que oírle" ${ }^{90}$. Algunos llaman este silencio prudencia ${ }^{61}$,

\footnotetext{
${ }^{54}$ Paravicino, en su poema "A la muerte... op. cit., f. 68v, califica al infante de "vivo enigma, real misterio". También se insiste en el secreto que rodeó al infante en el título del poema fúnebre de Antonio de Solís: "A la muerte del señor Infante don Carlos, considerando este infortunio a vista de la quietud misteriosa de su vida". Que don Carlos no solo fuera un enigma para los historiadores, sino también para sus contemporáneos, nos invita a indagar las razones de esta incógnita, demasiado tiempo resuelta falsamente por el argumento de la necedad del infante. Dado lo breve de este trabajo, únicamente pretendemos evidenciar esta problemática, esbozando solo algunos elementos de respuesta.

${ }^{55}$ El Cardenal infante ya tenía casa propia en 1622. Véase Houben, Birgit, "La casa del Cardenal Infante don Fernando de Austria (1620-1641)", en Millán, José Martínez y José Eloy Hortal Muñoz (coords.), La corte de Felipe IV (1621-1665): reconfiguración de la Monarquía católica, vol. 3, 2015, pp. 1679-1705. No se puede comparar la posición del infante Carlos en la corte de Felipe IV con la del Cardenal Infante, porque este último, gracias a su estatus de príncipe eclesiástico, gozaba de una libertad que, si era relativa en comparación con el grado de independencia que poseían segundogénitos de otras casas reales, era mucho mayor a la de Carlos. Así, por ejemplo, entre las noticias que llegaron de Madrid a Francia en 1632, se nos cuenta que el infante Fernando no quería renunciar al arzobispado de Toledo para “conserver sa maison, et ses officiers qu'il a depuis qu'il tient cette dignité apprehendant qu'apres estre despouillé on le mit au train de son deffunct frere et que pour tous serviteurs domestiques il n'eut qu'un valet de chambre”. Véase Institut de France, Ms Godefroy 495, Mélanges concernant l'Espagne, f. 206rv.

${ }^{56}$ Las numerosas relaciones de sucesos que circulan en los años 1620-1630 dan cuenta de ello.

${ }^{57}$ Justi, Carl, Velázquez y su siglo [1888], Madrid, Espasa-Calpe, 1953, p. 200: "Poco después [Velázquez] pintó el retrato del hermano del rey, don Carlos, de unos veinte años de edad. Se parece enteramente a Felipe, con la sola diferencia de la mandíbula inferior, más redondeada, y los ojos, más pequeños".

${ }^{58} \mathrm{~L} a s$ cuentas de mercaderes de sedas, lienzos y telas del rey dejan ver que se compraba lo mismo dos veces "para servicio de S. M. y Alteza". Por ejemplo, véase AGP, AG, Leg. 5251 (1).

${ }^{59}$ Hurtado de Mendoza, Antonio, Las señas... op. cit., f. 188v.

${ }^{60}$ Rodríguez de León, Panegyrico augusto... op. cit., f. 10r.

${ }^{61}$ Novoa, Matías de, Historia... op. cit., p. 194: "Era de altos pensamientos, sin ambición, y dificultoso de conocérselos, porque no era dado a revelarlos ni a que se los anteviesen sin causa, sino por forzosa razón de Estado, y en estos años últimos puso esto en cuidado a algún sujeto medroso"; Pellicer y Tovar, José, Oración fúnebre... op. cit., f. 10r: "Tu Prudencia, pues, te hizo tan advertido, que solo tú te conociste de cerca, que acá desde lejos te conjeturamos todos". "Relación de la muerte del Príncipe Carlos, hermano de F[elipe] IV, 30 de julio de 1632 " en
} 
aunque también resulta famosa la timidez del infante ${ }^{62}$. En todo caso, esta reserva enfatizó la impresión de insustancialidad que ya se desprendía de él debido a la carencia de libertad y de individualidad en la que vivía.

\subsection{Un infante silencioso y silenciado}

En sus memoriales, Olivares construye una imagen contrapuesta de los infantes Carlos y Fernando, la cual fue interpretada por la historiografía en desventaja de Carlos. Efectivamente, siempre es algo "menos" que Fernando: menos activo, menos letrado, menos peligroso; y hacia 1626 se nos describe a un joven de "condición fácil y rendida" ${ }^{3}$. Sin embargo, en su valiosa biografía del infante Carlos, Hurtado de Mendoza revela que el momento en que Felipe IV subió al trono resultó problemático por la "suma atención que tenía el Infante a la igualdad"64 en la que se habían criado los hermanos, que "mientras reinó su Padre, ninguna diferencia señaló al príncipe de los infantes sino el haber nacido primero" ${ }^{65}$. Estas anécdotas se hacen eco de un comentario que escribió el valido sobre el infante: "si bien [Carlos] no tiene noticia de las letras, no ignora la parte que le conviene" ${ }^{96}$, lo cual pone en tela de juicio la interpretación dominante según la que el hermano segundo de Felipe IV no tenía ninguna ambición política ${ }^{67}$. La alta consciencia que de sí mismo tuvo lo contradice. Si "supo ajustar el natural altivo tan al deseo de su hermano"68 como lo señala Pellicer, seguramente fue por las estrategias de control que se establecieron en torno a él desde el principio del reinado de Felipe IV ${ }^{69}$, las cuales debieron de surtir efecto en el adolescente intransigente que era, cortando de raíz las naturales ambiciones que hubiera podido mantener. De esta manera, si el embajador francés lo describe en 1621 "d'une humeur fort viollente et (...) capable de grandes choses en toute matiere" 70 , su sucesor escribe en 1632 que es "sy esgual en ces desirs que je pense que sy on luy offroit

Papeles varios de Felipe IV, BNE, Ms. 18175, f. 158r: "i giudicii che se ne fanno sono varii ma pero la maggior parte lo istimava prudentiss[imo]".

${ }_{62}$ Véanse los “Advertimientos del Conde-Duque al Señor Infante don Carlos" [1624], Apéndice XXI en Marañón, Gregorio, El Conde-Duque... op. cit., pp. 568-572.

${ }^{63} \mathrm{BL}$, Egerton Ms. 2081, fols. 261-267v; 278r: "Papel del conde duque de Olivares para el s[eñor] $\mathrm{Ph}[\mathrm{elipe}] 4^{\circ}$ en que se discurre sobre la colocazion de los s[eñores] Ynfantes D[on] Carlos y D[on] Fern[ando] hermanos de d[icho] s[eñor]", Madrid, domingo 13 de septiembre de 1626.

${ }^{64}$ Hurtado de Mendoza, Antonio, Las señas... op. cit., f. 177r.

${ }^{65}$ Ibidem, f. $175 \mathrm{v}-176 \mathrm{r}$.

66 "Informe del Conde-Duque al Rey sobre los Infantes, sus hermanos" [1632], Apéndice XX, en Marañón, Gregorio, El Conde-Duque... op. cit. p. 567.

${ }^{67}$ De hecho, en su interesantísimo artículo, S. Martínez Hernández ha demostrado que se había organizado una facción nobiliaria en torno al infante Carlos y que a este no le disgustaron las demostraciones públicas que se hicieron en su favor en el momento de la enfermedad del rey. Véase Martínez Hernández, Santiago, "Los más infames... op. cit., pp. 48-80.

${ }^{68}$ Pellicer y Tovar, José, Oración fúnebre... op. cit., f. 8v.

${ }^{69} \mathrm{~S}$. Martínez Hernández en "Los más infames... op. cit., p. 63, confirma que "el valido estableció un[a] estrecha vigilancia en torno a don Carlos, con el beneplácito de su hermano mayor".

${ }^{70}$ Du Fargis à Puisieux, Madrid, 6 mai 1621, BnF, Ms. Fr. 16118, f. 95r. El testimonio del embajador veneciano concuerda con el del embajador francés. Relazioni degli stati Europei lette al Senato dagli ambasciatori Veneti nel secolo decimosettimo, raccolte ed annotate da Nicolò Barozzi e Guglielmo Berchet, Serie 1, Spagna, Vol. I, Venezia, P. Naratovich, 1856-1860, p. 529: "L'infante don Carlos ha 14 anni, è di complessione confermata e molto robusta. Dà segni di dovere riuscire inquieto, di ingegno feroce, e inclinatissimo alla guerra”. 
demain destre chef d'un couvent ou d'une armée qu'il en dessereroit le choix a autruy"71. Esta aparente indiferencia, puesta de relieve por la evolución del carácter del infante, puede leerse más bien como la máxima expresión de una resignación interiorizada frente a la imposición de la autoridad del rey. Consideramos así que el carácter impasible del infante Carlos se debe en parte a un proceso de autocensura, faceta del deber de obediencia que le fue inculcado y que él asimiló a lo largo de los años en los que convivió estrechamente con Felipe IV.

\section{Un infante al servicio de la Monarquía Hispánica o unas esperanzas burladas}

Educado para obedecer, Don Carlos, con "su apacible y clarísimo natural"72, era el perfecto representante real para defender los intereses de la Monarquía Hispánica más allá de las fronteras de Castilla, listo para ejecutar cualquier orden del rey "al passo q[ue] fueren corriendo los empeños"73. Con su repentina muerte, quedaron vanas las innombrables horas que el Conde Duque gastó en "desvelo y meditación grande" "74; se malogró la cuidadosa formación a la sumisión que tan bien había asimilado el hermano de Felipe IV $^{75}$; y se vinieron abajo las esperanzas de triunfos futuros que naturalmente nutría la Monarquía Hispánica en la persona de don Carlos. De hecho, los elogios fúnebres recuerdan los pronósticos que habían adornado al infante desde su nacimiento, empezando por la gloria que auspiciaba un nombre heredado de su bisabuelo Carlos V, a quien se le imaginaba imitar, "añadiendo el Sexto a los Carlos de las dos Germanías"76. "Muro" de la Iglesia, capitán de España ${ }^{77}$, príncipe de "los reinos de Neptuno"78, el infante Carlos, destinado a las armas desde niño ${ }^{79}$, hubiera sido el héroe de un segundo Lepanto ${ }^{80}$, el "terror y asombro de las lunas turcas y berberiscas"

Que el rey pudiera emplear a su servicio a dos hermanos adultos y leales representaba una baza política considerable, sobre todo cuando, en medio de la guerra de los Treinta Años,

\footnotetext{
${ }^{71}$ Archives des Affaires Etrangères, Paris, P/12045, Correspondance des ambassadeurs de France en Espagne, 1630-1632. Monsieur de Peny à Monsieur Hotman, Sieur de Villers, Madrid, 26 juillet 1631, f. 239.

72 "Informe del Conde-Duque al Rey sobre los Infantes, sus hermanos" [1632], Apéndice XX, en Marañón, Gregorio, El Conde-Duque... op. cit., p. 567.

${ }^{73}$ AGS, EST, 2045, f. 45.

74 "El problema de los infantes" en Memoriales y cartas... op. cit., p. 163.

${ }^{75}$ Se trata de una afirmación que hemos alcanzado tras varios años de trabajo en torno a nuestra tesis doctoral, que actualmente llevamos a cabo, y donde desarrollaremos ampliamente esta cuestión.

${ }^{76}$ Pellicer y Tovar, José, Oración fúnebre... op. cit., f. 4r-v. En 1610, se barajó la posibilidad de presentar la candidatura de Carlos al Imperio, opción descartada por los consejeros de Estado por la pequeña edad del infante. Véase González Cuerva, Rubén, Baltasar de Zúñiga. Una encrucijada de la Monarquía Hispana (1561-1622), tesis doctoral, Universidad Autónoma de Madrid, 2010, p. 372.

${ }^{77}$ Ibidem, f. 25r-v.

${ }^{78}$ Calderón de la Barca, Pedro, Elegía en la muerte... op. cit., vv. 157-168.

${ }^{79}$ Bocángel, Gabriel, Retrato panegírico... op. cit., f. $16 \mathrm{v}$.

${ }^{80}$ Pellicer y Tovar, José, Oración fúnebre ... op. cit., f. 4v-5r.

${ }^{81}$ Novoa, Matías de, Historia ... op. cit., p. 198.
} 
España se enfrentaba a una penuria de "cabezas" ${ }^{22}$. Por tanto, la muerte de don Carlos sobrevino cuando más se le necesitaba, lo que desestabilizó la Monarquía Hispánica y mermó sus fuerzas. Oficialmente nombrado virrey de Portugal en abril de 1631, y Capitán General del mar en mayo de 1632, fue necesario encontrar a quién le reemplazara, proponiéndose infructuosamente estos cargos a los duques de Módena y de Parma ${ }^{83}$. Así, en la víspera de una ruptura abierta con Francia, de los dos brazos armados sobre los que planificaba apoyarse Felipe IV, solo le quedaba el Cardenal Infante Fernando.

\section{Conclusión}

Los años 1620-1630 resultan ser un verdadero laboratorio teórico en que se busca conceptualizar el estatus del infante de Castilla, hasta entonces obsoleto, ya que el último precedente se remontaba al siglo anterior. Los panegíricos fúnebres que celebran a don Carlos constituyen una buena prueba de la labor ideológica llevada a cabo en aquellos años para elaborar un modelo del hermano del rey. Muchas de las características que subrayamos en ellos repiten - y por tanto fijan y difunden públicamente- las ideas postuladas secretamente por Olivares en sus memoriales, principal fuente que aquí utilizamos. Tópico del desengaño barroco, el motivo del "morir naciendo" cobra un sentido muy concreto en el caso del infante Carlos, quien falleció cuando estaba a punto de franquear los opacos muros del Palacio Real gracias a lo que hubiera podido adquirir protagonismo y voz propia. Por tanto, los elogios fúnebres se erigen como ventanas poéticas por las que asomarse y captar parte de la esencia individual de este infante tan enigmático, sobre todo cuando, muy puntual y prudentemente, dan indicios de desaprobar el desajuste entre su aislamiento político y su dignidad de primer infante de Castilla. De hecho, la liberalidad con la que este protegió a numerosos cortesanos podría explicar por qué tantos literatos celebraron su figura, de la que aún resta mucho por conocer.

En todo caso, este "reloj" del infante de Castilla, dibujado teóricamente en la década 1620-1630 y fijado públicamente con la muerte de don Carlos, se confirmó aplicándose al Cardenal Infante durante los años bisagra 1632-1634, cuando se organizaron las diferentes etapas de su urgentísimo viaje a Flandes. Numerosas son las consultas de Estado que tratan del tema ${ }^{84}$. Sin sorpresa alguna, la principal preocupación seguía siendo la absoluta sumisión al rey

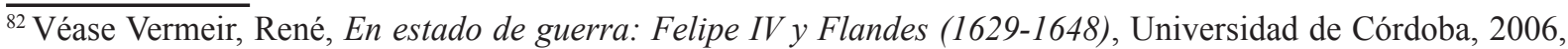
pp. 36-46.

${ }_{83}^{83}$ AGS, EST, 3338, f. 22.

${ }^{84}$ Quintín Aldea Vaquero recoge buena parte de estas en España y Europa en el siglo XVII: correspondencia de Saavedra Fajardo, Tome 3, El Cardenal Infante en el imposible camino de Flandes, 1633-1634, Madrid, Consejo superior de investigaciones científicas, Real Academia de la historia, 2008.
} 
que había de observar el Cardenal Infante, sabedor de "la obligación que t[enía] en conciencia a no tener más dictamen que obedecer a la letra las órdenes de V. M." ${ }^{95}$.

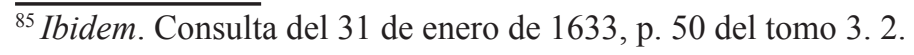

